\title{
CARTOGRAFíAS PAN/AMERICANAS EN COCINA ECLÉCTICA (1890) DE JUANA MANUELA GORRITI'
}

\author{
ROCÍO FERREIRA \\ DePaul University
}

Dos años antes de su muerte, Juana Manuela Gorriti (1818-1892) publicó Cocina ecléctica (1890); libro que reúne las recetas culinarias que les solicitó a sus amigas de diversos lugares de Hispanoamérica para su publicación. Este último ejercicio comunitario que Gorriti organizó denota su interés por representar la diversidad pan/americana y de forjar la participación de la mujer en el ámbito cultural; gesto que iniciara a su llegada al Perú con su labor como escritora y salonnière. Gorriti fue una de las intelectuales más activas e importantes de su época ya que fue la que dio mayor empuje a la participación de la mujer en el ámbito de la cultura literaria a lo largo de una vida agitada de interminables viajes entre Lima y La Paz, Salta y Buenos Aires $^{2}$. Se estableció en el Perú (primero en Arequipa y luego en Lima) a mediados de la década de los años cuarenta donde residió por un período de más de treinta -interrumpidos- años. Durante su larga estadía en el Perú, Gorriti comenzó su carrera como intelectual y escritora publicando leyendas sentimentales y artículos de temas variados en

1

Una versión de este trabajo fue presentada en el Coloquio Internacional: «100 años después. La literatura de mujeres en América Latina: el legado de Mercedes Cabello de Carbonera y Clorinda Matto de Turner», California, State University, Long Beach, Mayo 2009, y saldrá publicada próximamente en las Actas del Coloquio. revistas y semanarios justamente en la época en la que los estadistas peruanos comenzaban a forjar proyectos nacionales para organizar la joven república bajo la dirección del general Ramón Castilla (1845-1851 y 1855-1864) ${ }^{3}$. Ya en 1860, Gorriti había alcanzado una gran reputación en la vida intelectual limeña con la publicación inicial por entregas en 1851 de su leyenda peruana «La quena», en el «Folletín» del diario $\mathrm{El} \mathrm{Comercio}{ }^{4}$; con publicaciones en La Revista de Lima y La Revista de Buenos Aires; con la fundación de tres importantes semanarios dirigidos a mujeres -El Albúm (1874, con Carolina Freire de Jaimes), La Alborada (1874-75) y La Alborada del Plata (1877-80)- y, finalmente, con la instauración de su famoso salón literario (1876-77). Asimismo, «la embajadora cultural» se incorporó rápidamente al grupo de «los bohemios» como una figura de gran respeto y admiración. En La bohemia de mi tiempo Ricardo Palma afirma, «Los bohemios la tratábamos con la misma llaneza que a un compañero, y su casa era para nosotros un centro de reunión» ${ }^{5}$. A partir de este momento, la escritora argenti-

Isidoro Belzú, -caudillo y futuro presidente de Bolivia- con quien tuvo dos hijas: Edelmira y Mercedes. Después de vivir varios años en Bolivia, se trasladó a Arequipa en 1845 con su familia ya que la actividad política de Belzú los llevó al exilio. Después de separarse de Belzú se refugió en Arequipa en primera instancia -donde fue gran "animadora de la vida social»- para fi-

1848. En Lima tuvo dos hijo más -Clorinda Puch y Julio F. Sandoval- quien más tarde se convirtió en su compañero co-organizador y compilador de las veladas literarias. En 1877 Gorriti regresó a Buenos Aires para recibir una pensión vitalicia que la obligó a residir allí hasta el día de su muerte en 1892. En 1881, después de permanecer en Chincha
Rocío Ferreira:

Rocío Ferreira obtuvo el doctorado en literatura latinoamericana y estudios de género en la Universidad de California en Berkeley y ahora es catedrática de literatura latinoamericana en la Universidad DePaul en Chicago. Trabaja en temas relacionados con la literatura latinoamericana de los siglos XIX, XX y XXI y teoría de género, pero su investigación se enfoca principalmente en la cultura y literatura peruana. Ha participado en numerosos congresos internacionales y publicado artículos de crítica en libros y revistas especializadas. Su libro De las Veladas literarias a la Cocina ecléctica: mujeres, cultura y nación en el Perú decimonónico está por salir con el Fondo Editorial del Congreso del Perú. El Centro de Humanidades y el Centro de Investigación Latino/americano de DePaul le ha otorgado una beca para que continúe trabajando en su proyecto actual titulado «Yuyanapaq/para recordar: Memoria, desplazamiento y violencia política en la cultura peruana contemporánea».

durante la Guerra del Pacífico con su amiga Mercedes Cabello de Carbonera, se instaló en Buenos Aires y sólo regresó al Perú en 1884 de visita.

3

El importante rol que ejerciera Gorriti en el desarrollo de la cultura literaria peruana de la segunda mitad del siglo XIX lo he desarrollado ampliamente en mi trabajo inédito: "De cómo dejarse caer de la sartén al fuego de la escritura: la narrativa peruana de Juana Manuela Gorriti».

4

Cf. mi artículo «Transacciones de amor y de dinero: oro, género y domesticidad en las leyendas 'Andinas' de Juana Manuela Gorriti», en Sara Beatriz Guardia (ed.), Mujeres que escriben en América Latina, Lima, CEMHAL, 2007, pp. 163-76.

5

Ricardo Palma, La bohemia de mi tiempo, Lima, Ediciones Hora del Hombre, 1948, p. 30.
Cartografías pan/americanas en Cocina ecléctica (1890) de Juana Manuela Gorriti

ROCÍO FERREIRA 


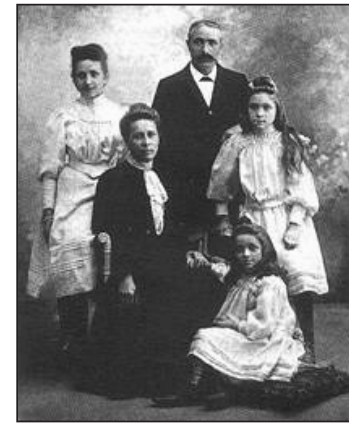

Familia Gorriti.

6

Sobre Cocina ecléctica tres ensayos abrieron el campo de estudio de este poco conocido texto de Gorriti. Véase Nina M. Scott, «Juana Manuela Gorriti's Cocina eclectica: Recipes as Feminine Discourse», Recipes for Reading Community Cookbooks, Stories, Histories, Amherst, University of Massachusetts, 1997, pp. 18999 (este artículo apareció primero en Hispania 75 (May 1992), pp. 310-14; Josefina Iriarte y Claudia Torre, "Juana Manuela Gorrti: Cocina ecléctica. 'Un sí es no es de ajo molido'», Mujeres y cultura en la Argentina del siglo XIX, Buenos Aires Feminaria Editora, 1994, pp. 80-86; y "La mesa está servida», El ajuar de la patria, Buenos Aires, Feminaria Editora, 1993, pp. 45-61.

7

Hago alusión al libro editado por Anne L. Bower, Recipes for ..., op. cit.

8

Juana Manuela Gorriti, Cocina ecléctica, Buenos Aires, Félix Lajouane, 1890. El epígrafe que abre esta sección y las citas de las recetas provienen del texto original. Todas las citas de este ensayo mantendrán la ortografía y puntuación original. También hemos consultado otras ediciones más recientes del texto y hemos constatado que no son fieles a la versión original. Por ejemplo la edición publicada por la Librería Sarmiento S.R.L, omite varias recetas como por ejemplo la de «Ensalada de paltas» de Mercedes Cabello de Carbonera, entre otras. Véase Juana Manuela Gorriti, Cocina ecléctica, Buenos Aires, Librería Sarmiento S.R.L., 1977. La edición

Cartografías pan/americanas en Cocina ecléctica (1890) de Juana Manuela Gorriti

ROCÍO FERREIRA

na sostuvo una gran amistad con el escritor tradicionista Ricardo Palma y con las escritoras Clorinda Matto de Turner y Mercedes Cabello de Carbonera. Además, fue la madre intelectual, maestra y amiga de las escritoras peruanas que se iniciaban en las letras y con ellas, precisamente, fue con quienes dialogó en su salón literario; el más prestigioso de Hispanoamérica. Fue en ese espacio donde las jóvenes escritoras cuestionaron sin tregua asuntos relacionados con la formación de las naciones, la situación de la mujer, la constitución de la familia, el matrimonio, la educación, y su propia participación en el mundo intelectual. Por lo demás, la producción literaria de Juana Manuela Gorriti cubre un amplio territorio en el campo cultural decimonónico hispanoamericano, pues va del punto más álgido del romanticismo hasta el positivismo de fin de siglo. Así, desde sus primeras leyendas romántico-sentimentales hasta la publicación de Cocina ecléctica (1890) -texto del que nos ocuparemos en este ensayo-, pasando por los temas polémicos presentados en sus veladas literarias, $y$, sobre todo, por sus distintas narraciones vemos que la obra de Gorriti está atravesada por un discurso americanista que está muy presente en su último proyecto: el libro de cocina ${ }^{6}$.

En este artículo nos proponemos ver algunas particularidades de este compendio de recetas culinarias que nos interesan destacar en nuestro corpus en relación al enfoque pan/ americanista del texto y a la experiencia cultural de Juana Manuela Gorriti en el Perú. Como observaremos, muchas de las autoras de las recetas publicadas en Cocina ecléctica son las escritoras y/o educadoras que participaron en sus veladas literarias de Lima; mientras que otras de ellas están directamente vinculadas con los intelectuales y los estadistas peruanos o con los invitados hispanoamericanos que fueron asiduos colaboradores en las tertulias semanales; además de sus amigas y parientes bolivianas y argentinas. A su vez, dada su fascinante pluralidad y riqueza, el compendio de recetas configura una notable reflexión, no sólo sobre la cocina y sus elementos innatos en sí, sino también sugiere nítidamente que

de Martorell, aunque incluye todas las recetas, no deja de tener algunas fallas mínimas como invertir el orden de dos recetas, por ejemplo. Véase
Juana Manuela Gorriti, Cocina ecléctica, Alicia Martorell (ed.), vol. 3, Salta, Fundación del Banco del Noroeste Coop. Ltdo., 1989, pp. 147-354. a través de este espacio "doméstico», marginado («la cocina») pero propio, se cocinan ciertos saberes que van más allá de una receta, como veremos a continuación. En función de lo que hemos expuesto, en este ensayo nuestro interés principal se centra en ilustrar la diversidad de discursos que traen en sí mismas las recetas y ver la relación que éstas presentan con la ideología particular de las autoras.

\section{Recetas para leer ${ }^{7}$}

«Helado de canela»8

Pues que las letras se permiten el solaz de bajar á la cocina, ¿por qué nó el magisterio, cuya mision es también, enseñar lo bueno? - Enriqueta Lund (Lima)-

Es claro que a través de los años la cocina ha servido y sigue sirviendo como punto de reflexión para desarrollar y explicar historias, teorías, filosofías y demás. Al repasar la historia americana no tardamos mucho en encontrar escritores, filósofos, críticos, estudiosos que han desarrollado y expresado sus ideas a partir de metáforas culinarias a lo largo de los siglos. Sólo nos basta recordar, por ejemplo: el relato que nos cuenta el Inca Garcilaso de la Vega sobre la experiencia de lo chasquis y los melones «jabladores»; la interpretación del intercambio del vaso de chicha que hace Felipe Guaman Poma de Ayala del (des)encuentro entre Atahualpa y Francisco Pizarro en Cajamarca; «los secretos naturales» que descubre Sor Juana Inés de la Cruz guisando; el aprecio americano que hace Andrés Bello en su poesía al exaltar sus frutos; la desgarradora descripción de la condición de las «Cocinas y cocineras» peruanas que deta1la Abelardo Gamarra; el dolor profundo que emana del "pan nuestro» de César Vallejo; el diálogo que entabla Alfonsina Storni entre la tragedia clásica y la realidad de una cocinera en su breve texto «Polixema y la cocinerita»; la glorificación de los alimentos y cosas cotidianas que en «Odas elementales» compone Pablo Neruda; el «Manifesto Antropófago» de Oswald de Andrade; el valor que le da Gilberto Freyre a la cocina nordestina en su «Manifesto Regionalista»; la imagen culinaria de un ajiaco caribeño que ofrece Fernando Ortiz para explicar su teoría de la «transculturación»; las »naranjas y manzanas» filosóficas de Clarice Lispector. Además varias escritoras 
y críticas literarias contemporáneas también se sirven del espacio tradicionalmente femenino, «la cocina», como un lugar de reflexión en su escritura. Por ejemplo: la «Lección de cocina» de Rosario Castellanos; el título de la compilación de ensayos de Patricia González y Eliana Ortega, La sartén por el mango; el ensayo crítico «La cocina de la escritura» de Rosario Ferré; los recetarios que Debra A. Castillo incluye al principio y al final de Talking Back; el libro de recetas afrodisiacas de Isabel Allende, Afrodita; y las novelas Como agua para chocolate: novela de entregas mensuales, con recetas, amores y remedios caseros e Íntimas suculencias: tratado filosófico de cocina de Laura Esquivel. Por otro lado, cabe mencionar que, cien años después de que Gorriti publicara su libro «comunitario» de recetas de cocina con la contribución de un heterogéneo grupo de mujeres latinoamericanas célebres, en este fin de siglo en el Perú se han trabajado proyectos similares. Por ejemplo, el poeta Antonio Cisneros organizó y publicó en el 2000 un recetario culinario titulado $E l$ diente del Parnaso. Manjares y menjunjes del letrado peruano con la contribución de hombres célebres, y por otro, las mujeres de sectores marginales siguen luchando juntas por mejorar el movimiento que crearan hace más de dos décadas - «la cocina comunitaria»- para alimentar nutritivamente a su comunidad. Como en el siglo pasado, las mujeres y los hombres usan el espacio doméstico de la cocina para enfrentarse con los problemas sociales y políticos contemporáneos. Sobre este tema, Deane W. Curtin y Lisa M. Heldke en Cooking, Eating, Thinking. Transformative philosophies of food subrayan la resonancia que los alimentos tienen en la formación de sociedades, de sus individuos e identidades, así como la necesidad de profundizar en la relación central que existe entre estos.

En su importante trabajo sobre las escritoras argentinas, Francine Masiello ha demostrado que

los estudios culturales, inspirados fundamentalmente en las estrategias deconstructivistas, han revisado la oposición tradicional entre la esfera pública y la privada -cuya vinculación con el género resulta arbitraria-, según la cual las actividades masculinas están situadas decididamente en el ámbito público, mientras que las femeninas están relegadas al dominio del hogar. Estas categorías de análisis han sido objeto de investigaciones que cuestionan las falsas dicotomías implícitas en lo 'público' y lo 'privado'. Se trata de un proceso de develamiento a fin de demostrar la permeabilidad constante entre ambos dominios de la experiencia9.

Conviene en este punto precisar algunos de estos conceptos críticos que son los que han posibilitado nuestra genealogía del discurso literario femenino en el siglo XIX. La cocina, como las veladas literarias limeñas en su «modesto salón», espacios domésticos accesibles a toda mujer, se vuelven espacios de participación pública, en los que se producen discursos que van más allá de una receta o una charada. Las mujeres dialogan públicamente acerca de la cultura y de la historia y prueban que, como dice Masiello, «la escritura doméstica se convierte en una manera de ampliar un diálogo sobre la adquisición del conocimiento y de la ciencia y modos de afectar los programas del Estado» ${ }^{10}$. En ese sentido, las recetas recogidas en Cocina ecléctica pueden ser pensadas como «espacios imaginarios» a través de los cuales es posible leer dentro de los temas, ideas y cuestiones del proyecto americanista que interesaban a las contribuyentes.

¿En qué consiste el «saber» alternativo de las rececetas? Claramente deducimos que este texto fue montado por Juana Manuela Gorriti para establecer su propuesta pan/americanista en un diálogo imaginario con múltiples y diversos lectores en torno al reto que representaba la construcción de un proyecto nacional en Hispanoamérica. ¿Cuál fue la relación entre la producción literaria de las escritoras y la(s) receta(s) que cuidadosamente escogieran para esta publicación? Para las autoras las recetas literarias y culinarias se definen como parte de la ideología decimonónica. Las recetas deslizan su mirada hacia sus propios proyectos. Se trata de establecer un diálogo intertextual entre la ideología que ciertas autoras desarrollan en su obra y las recetas que elaboran para la antología. Hablando del caso particular de las escritoras peruanas, en ellas se materializa el discurso indigenista y anticlericalista de Clorinda Matto de Turner; el positivismo científico de Mercedes Cabello de Carbonera y la preocupación por la educación femenina de Teresa González de Fanning, por ejemplo. En el caso de Gorriti, el recetario le sirve para trazar una cartografía personal y cultural en la que favorece a los países en los cuales residió. Además estas autoras revisan el rol de la mujer en la historia y su sociedad actual.
9

Francine Masiello, Entre civilización y barbarie. Mujeres, nación y cultura literaria en la Argentina moderna, Rosario, Beatriz Viterbo Editora, 1997, p. 20.

10

Masiello, op. cit., p. 21
Cartografías pan/americanas en Cocina ecléctica (1890) de Juana Manuela Gorriti

ROCÍO FERREIRA 


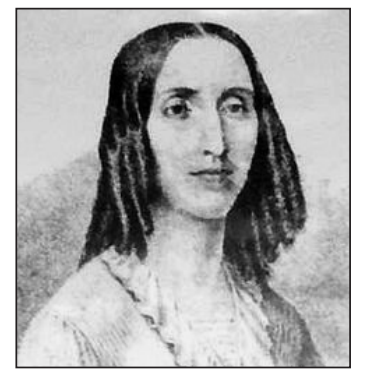

Juana Manuela Gorriti (18181892).

11

Juana Manuela Gorriti, «Chincha», El mundo de los recuerdos, Buenos Aires, Félix Lajouane, Editor, 1886, pp. 311-21. Este mensaje se lo leyó Juana Manuela a sus comensales -su querida amiga Mercedes Cabello de Carbonera, el Dr. Urbano Carbonera y su hijo Julio F. Sandoval- «reunidos en torno a la mesa» durante su estadía en Chincha, Perú.

12

Gorriti, Ibid., p. 317.

13

Gorriti, Ibid., p. 322.

Cartografías pan/americanas en Cocina ecléctica (1890) de Juana Manuela Gorriti
A rastrear esta hipótesis están dedicadas las siguientes secciones de este estudio.

La cocina (ecléctica) de la escritura en el proyecto pan/americanista de Juana Manuela Gorriti

\section{Señores: Mensaje.}

[...] Como base de toda operacion culinaria, he procurado dar al conjunto del menaje la limpieza esmerada, que necesita, sobretodo, en este lugar de continuas polvaredas. [...]

En busca de modificaciones que se adapten á todos los gustos, he ideado para la salsa de peregil en reemplazo del desagradable queso, el migajon de pan desleido en la crema de leche, que le da un sabor delicioso; sustituyendo para esta y la de mirasol, el aromático jugo de la naranja, al indigesto vinagre. $\mathrm{He}$ cambiado el uso de verduras trituradas en la confeccion del puchero, con un manojo de yerbas olorosas que, cocidas con la carne, dán á esta y al caldo, un sabor agradable.

En el anhelo de extender el catálogo de nuestros manjares, he hecho apelacion á los recuerdos de mi vida nómada, y tomado de los diferentes países que me albergaron, lo que encontré digno de nuestro delicado paladar; y os he servido el estofado de seis carnes, la ensalada de zapallo en flor; umintas y pasteles asados entre piedras calcinadas, y la carne con cuero de la Pampa natal ${ }^{11}$.

La cita que inicia esta sección presenta a Gorriti al mando de la cocina en «la casita preciosa». En la narración «Chincha», Gorriti relata el viaje que hiciera con su querida amiga Mercedes Cabello de Carbonera y su hijo Julio F. Sandoval al tranquilo pueblo ubicado en Ica, al sur de Lima, huyendo de la nefasta «Guerra del Pacífico». Lo interesante de este relato es que revela -a través de la serie de recetas que ella le presentara a sus comensales- su filosofía de la vida. En su descripción, Gorriti pone énfasis en buscar modificaciones «que se adapten a todos los gustos». Para conseguir su objetivo Gorriti idea, reemplaza, sustituye, cambia, apela a los recuerdos de su vida nómada y finalmente toma de los diferentes países que la albergaron -Argentina, Bolivia y Perú- aquello que encuentra digno del delicado paladar de los comensales y suyo. La concepción del arte culinario de Gorriti conserva una relación metonímica con su quehacer literario. Cocinar es escribir y un ingrediente o una receta es un lugar de esa car- tografía triangular. Asimismo, a lo largo de su carrera de escritora viajera, Gorriti -al igual que en la cocina- escogería cuidadosamente ingredientes netamente americanos para confeccionar sus relatos y estos, a su vez, le servirían para organizar un juego de alianzas. En este sentido es especialmente interesante que este relato establezca la importancia que las escritoras decimonónicas dieran a la amistad y a las relaciones humanas basadas en un sistema de reciprocidad andina.

Este sistema organizativo andino sufrió cambios a lo largo de los años para adaptarse a nuevas situaciones pero nunca fue erradicado. En el relato "Chincha» las dos amigas, Cabello y Gorriti, deciden habitar «la preciosa casita amueblada» que el Doctor Carbonera había arrendado para Gorriti y su hijo; deciden enviar a Julio, el hijo, a casa del Dr. Carbonera para que le haga «compañía al esposo abandonado». Gorriti cuenta: «Endulzamos el forzado convenio, prometiendo á aquellos señores las delicias de una esquisita mesa, cuyo menu, dirijido alternativamente por las dos amas de la casa, nada dejaria que desear» ${ }^{12}$. Gorriti y Cabello regalan dadivosamente al hijo y al esposo con «esquisitos platos» para asegurarse de que su petición no fuera rechazada. La reciprocidad fue la estrategia más importante que Gorriti utilizó para crear «aquella existencia de dulce fraternidad» que siempre anheló y logró ${ }^{13}$.

Cocina ecléctica de Gorriti es la muestra final del incansable esfuerzo de esta prodigiosa mujer por estrechar siempre los lazos «sororales» (más que fraternales, dada la estrechísima amistad entre estas mujeres) entre uno y otro lado de la Cordillera de los Andes en base al sistema organizativo andino de la reciprocidad. En su libro de «preciosos materiales» Gorriti recopila las recetas especiales de sus queridas amigas no para saciar el apetito de maridos sino más bien para alimentar el alma de quien produce y recibe una delicia. Un ejemplo sobresaliente de este intercambio cultural y espiritual en el que las mujeres dialogan es la receta «Ensalada de Paltas» que Mercedes Cabello de Carbonera le enviara a su amiga para ser publicada en Cocina ecléctica. En esta receta Cabello evoca los días que las dos amigas pasaran juntas en Chincha:

La compiladora de estas eclécticas recetas, ha gustado muchas veces este riquísimo plato, preparado por mí, allá en los días felices que pasamos juntas, habitando 
aquel poético pueblecito, escondido como el nido de una ave, entre bosques de naranjos y limoneros, donde no teníamos mas trabajo que tender la mano, para cosechar las frutas más esquisitas.

Allí cogía yo las paltas de la ensalada que tomábamos en ayunas, para mejor saborearla, y como aperitivo al próximo almuerzo.

Es tan sabrosa y delicada la pulpa de esta fruta, verdadera maravilla tropical, que toda especie está de más, en su condimento, debiendo, para esta, emplearse solo aceite, vinagre, sal, y, á lo más, un ligero espolvoreo de pimienta.

Si ha de servirse en una mesa, se le pone al centro, como relieve, una palia, sobre hojas tiernas de lechuga $a^{14}$.

La palabra escrita que narra anécdotas y describe la elaboración de variados y suntuosos platillos y bebidas regionales americanos, y uno que otro europeo, borra la distancia entre las emisoras y la receptora al evocar recuerdos de otras tierras, de otros tiempos, de momentos compartidos, a través de todos los sentidos: el tacto, la vista, el olfato y el gusto.

Con Cocina ecléctica Gorriti dibuja un nuevo mapa cultural en el cual su trayectoria de vida está presente: Argentina, Bolivia y el Perú15. En este sentido, las recetas, como los conceptos, son también imágenes del pensamiento. Tal vez por este motivo, y ya que en realidad el mismo texto aspira a ser una ilustración de ese mapa cultural, en el que en cada receta se dibuja ya sea una memoria, una emoción o una percepción, Gorriti no incluiría ninguna receta propia. La constelación de recetas -que privilegia las regiones que permanecieran latentes en su «mundo de los recuerdos»- será la que configure la cartografía imaginaria de Gorriti.

Nuevamente, mujeres de distintos ámbitos se conectan por medio de la cultura, y cantan polifónicamente la diversidad latinoamericana:

... a través de más de doscientas recetas de los bocados más exquisitos que contienen las cocinas peruana, boliviana y Salteña.

Salteña, digo, y no argentina, porque de nuestras catorce provincias solo Salta tiene una cocina propia... ${ }^{16}$.

A la vejez, Gorriti organizaría este nuevo proyecto en el que le solicitaría a sus amigas (escritoras, educadoras, alumnas, monjas, fa- miliares y conocidas) que le enviasen sus recetas favoritas para publicarlas en un libro de cocina. Un proyecto que sería acogido con gran ilusión por múltiples contribuyentes. Ciento setenta y siete mujeres, aproximadamente ${ }^{17}$, enviarían doscientas cuarenta y cuatro recetas, en muchos casos comentadas, desde Salta, La Paz, Cochabamba, Oruro, Santiago, Limache, Cusco, Arequipa, Lima, Tacna, Tarma, Buenos Aires, Córdoba, Rosario, Metán, Mendoza, Tucumán, Santa Fe, Flores, La Plata, Montevideo, México, Bogotá, París, Sevilla, La Rioja, San Sebastián, Anvers, Dublin y Nueva York. En este intercambio cultural -en el que las amigas mandan el material y ella lo publica- Gorriti logra establecer un círculo social que les permitiría a las contribuyentes publicar e intercambiar ideas no sólo a nivel nacional sino internacional.

A primera vista, Cocina ecléctica pareciera ser un libro común de recetas culinarias, sin embargo una lectura detenida de cada receta demuestra que el compendio es un reflejo de la cultura decimonónica en la que se desarrollaron estas mujeres. Detrás de la cocina se despliega la historia latinoamericana circundante que gira alrededor de las experiencias e intereses personales de las contribuyentes. En el mapa cultural que Gorriti establece están presentes la historia pre-colombina, colonial y republicana; así como referencias a: guerras, héroes, generales, zonas geográficas específicas y productos oriundos de la zona andina entre otros. Además las autoras narran sucesos curiosos, llenos de un celo nacionalista, con el afán de autorizar «la gracia encantadora de su palabra» (la palabra escrita) que explica la preparación «de las confecciones suculentas». Para la compiladora «las confecciones suculentas» propias no son otras que las literarias, por eso ella se autoriza nombrando, primero, al memorialista francés Brantôme, a los escritores de la antigüedad y sobre todo a los románticos franceses; mientras que las colaboradoras le dan prestigio a sus manjares a través del éxito consagrado de sus recetas ya comprobado con paladares exquisitos. La lista de autoridades incluye el paladar del Inca, del caudillo Artigas, de indios, gauchos, guasos y frailes, de padres, de un hermano -a quien la autora compara con el gastrónomo y escritor francés Brillat-Savarin-, del escritor francés Scarron, de la cantante italiana de ópera Adelina Patti, de Napoleón, de cónsules, de gastrónomos y cocineros anónimos, de la célebre

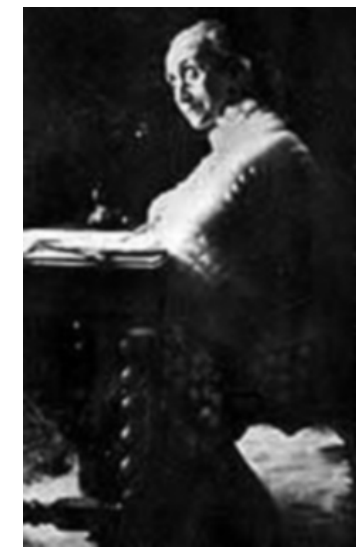

Juana Manuela Gorriti.

14

Gorriti, ibid., p. 289

15

Gran parte del territorio que Ángel Rama denominara "el área cultural andina» en Transculturación narrativa en América Latina, México, Siglo Veintiuno Editores, 1987.

16

Juana Manuela Gorriti, Lo íntimo, Alicia Martorell (ed.), vol. 12, Salta, Fundación del Banco del Noroeste Coop. Ltdo., 1989 (pp. 70-195), p. 143-44.

17

Digo aproximadamente, porque varias autoras usan distintas estrategias para publicar más de una receta. Algunas cambian sus nombres ligeramente, usan iniciales o alternan entre el apellido de soltera y el de casada. Por ejemplo una autora firma: Mercedes Torino de Pardo, Mercedes Pardo y Mercedes T. de Pardo. Otra autora -posiblemente Urcina Ponce de Sandoval, esposa de su hijo Julio F. Sandoval- firma su última receta con su seudónimo "Chinga» y comenta en el libro: "Achacarían á falta de modestia, si vieses ya tres veces repetido mi nombre en este libro. Por tanto, al ofrecerle una nueva confeccion, será bajo el dulcísimo diminutivo con que me nombran los míos, muy más querido para mí que todos los títulos de la tierra».

Cartografías pan/americanas Cocina ecléctica (1890) de Juana Manuela Gorriti

ROCÍO FERREIRA 


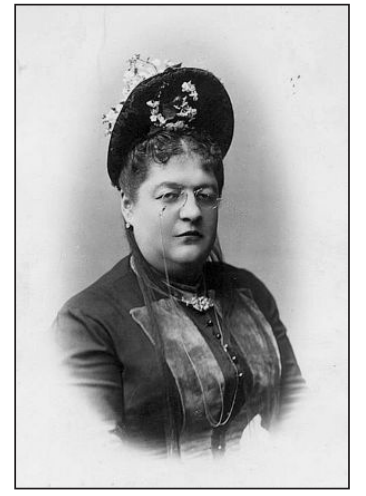

Clorinda Matto de Turner.

\section{8}

La letrilla fue escrita en Lima, el 28 de octubre de 1877 . Véase Mercedes Cabello de Carbone$\mathrm{ra}$, "Mujer escritora», Almanaque de la broma para 1878, Eloy Buxó, Lima, Imprenta del Estado, 1877. El editor de Almanaque de la broma Eloy $\mathrm{P}$. Buxó le respondió a Mercedes Cabello con su letrilla titulada "Marido poeta». Mientras que la letrilla de Cabello demuestra el rechazo de los hombres hacia la mujer escritora fundamentado en una marginalización de género, la letrilla de Buxó pone al relieve la desestimación de las mujeres hacia el marido poeta basado en su condición económica. Además, Buxó también con humor hace referencias a los nuevos ricos empresarios guaneros.

19

Maritza Villavicencio, Del silencio a la palabra: mujeres pervanas en los siglos XIX-XX, Lima, Flora Tristán, 1992, p. 56.

20

Gorriti, Cocina ecléctica, op. cit. s/p.

21

Nina M. Scott menciona la semejanza de la estructura de Cocina ecléctica con los recetarios comunitarios "community cookbooks» estadounidenses que se popularizaron alrededor de la Guerra Civil: «lt seems entirely possible to me that Gorriti heard of the fund-raising cookbooks which were popular in the United States via one of these teachers invited to Argentina by President Domingo Faustino Sarmiento in 1866», op. cit., p. 192.

Cartografías pan/americanas en Cocina ecléctica (1890) de Juana Manuela Gorriti

monja María Serrano, de la Reina Victoria y de los «childs galles».

Como compiladora, Gorriti se encarga de escribir el prólogo y de abrir algunas de las secciones del libro de cocina con notas explicativas. En el prólogo Gorriti avala la importancia de su proyecto estratégicamente reconciliando dos vocaciones creativas pero que en su época se consideraban dispares en la mujer: la escritura (espacio masculino) y la cocina (espacio femenino). En este contexto cabe mencionar la letrilla "Mujer escritora» que publicara Mercedes Cabello en 1877 en El almanaque de la broma, -colección de poemas, cuentos y encrucijadas de tono irónico. En esta letrilla Cabello critica con gran humor la ideología dominante de la sociedad moderna frente a la nueva intelectual: «Lo digo y repito/ y juro que nunca / tendré por esposa / mujer escritora. //¿Qué sirven mujeres/ que en vez de cuidarnos / la ropa y la mesa, / nos hablan de Byron, / del Dante y Petrarca, / cual si esos señores, / lecciones les dieran / del modo que deben / zurcir calcetines / ó hacer un guisado? / Lo juro, no quiero / mujer escritora // Mujer literata, / por mucho que sepa /es plaga maldita /» ${ }^{18}$.

En esta letrilla Cabello de Carbonera evidencia «el temor que abrigaban muchos hombres a que las mujeres pensasen y fueran capaces de abordar actividades distintas a aquéllas que no fueran las domésticas o las relacionadas con el hogar» ${ }^{19}$. Sin embargo a pesar de las presiones que la sociedad imponía en la «mujer escritora»-es decir, que se limitara a ejercer en el territorio considerado propio de la mujer- no dejaría ni de escribir ni de criticar a las instituciones y leyes de una sociedad patriarcal represiva y violenta.

\section{2}

Aunque estas categorías no se borrarían. Un ejemplo de las marcadas jerarquías que se exhiben en la cocina es la receta «Pastelitos de huevo a la nena» de Carolina L. de Castilla (Buenos Aires), en la que se le niega la autoría de la receta a la cocinera Ursula tanto en el título como en la firma. Gorriti, Cocina ecléctica, op. cit.

La picaruela sueña con ellos en el colegio los treinta días del mes.

«Así, tambien, desde que llega á la casa, y no bien recibe los besos maternos corre á la cocina.

$-\dot{\text { ¿Y }}$-demanda con autoridad á la despota del fogon.
Las escritoras usan estratégicamente el espacio doméstico del hogar para ejercitar la escritura, para criticar ciertas prácticas excluyentes y marginalizadoras, y sobre todo para convocar a su círculo de mujeres:

el hogar es el santuario doméstico; su ara es el fogon; su sacerdotisa y guardian natural, la mujer.

Ella, solo ella, sabe inventar esas cosas exquisitas, que hacen de la mesa un encanto, y que dictaron á Brontome el consejo dado á la princesa, que le preguntaba cómo haría para sugetar á su esposo al lado suyo:

-Asidlo por la boca.-

Yo, jay! nunca pensé en tamaña verdad.

Avida de otras regiones, arrojéme á los libros, y viví en Homero, en Plutarco, en Virgilio, y en toda esa pléyade de la antigüedad, y despues en Corneille, Racine; y más tarde, aún en Chateaubriand, Hugo, Lamartine; sin pensar que esos ínclitos genios fueron tales, porque -excepcion hecha del primero- tuvieron todos, á su lado, mujeres hacendosas y abnegadas que los mimaron, y fortificaron su mente con suculentos bocados, fruto de la ciencia más conveniente á la mujer.

Mis amigas, á quienes, arrepentida, me confesaba, no admitieron mi mea culpa, sino á condicion de hacerlo público en un libro.

Y, tan buenas y misericordiosas, como bellas, hanme dado para ello preciosos materiales, enriqueciéndolos más todavía, con la gracia encantadora de su palabra ${ }^{20}$.

En éstas líneas Gorriti ocupa el lugar de la sacerdotiza de la cocina y, como escritora que es, se sitúa en el mismo lugar de eximios escritores que cita y reconoce que, como ellos, necesita de la colaboración y del apoyo fortalecedor de «mujeres hacendosas» para poder llevar a cabo su proyecto. Sin embargo, a diferencia de ellos, las amigas mutuamente se envigorizan intelectual y espiritualmente con la preparación del manjar deseado; «la crema de la crema»: el libro comunitario ${ }^{21}$ y colectivo.

El círculo internacional de participantes que este proyecto reúne está conformado no solo por mujeres burguesas sino también por mujeres provenientes de diferentes estratos sociales, raciales y económicos. La cocina se convierte en un terreno donde ciertos antagonismos - de clase, raza, religión, geografía- se pasan por alto y es aún posible que se dé esta convivencia con una complicidad aparente entre las participantes ${ }^{22}$. El texto en sí, se de- 
sarrolla a partir de una concepción dinámica de la cultura. Por ejemplo, participan Lucila Cabello y María Santillana, ex-alumnas de su escuela limeña; sus hijas Edelmira y Mercedes; su nuera Urcina Ponce de Sandoval; la negrita Encarnación (cocinera salteña); sus sobrinas y primas; dos monjas: Sor Carmen de la Portilla y Sor María del Socorro; esposas de generales y escritores; sus amigas escritoras como la poeta boliviana Adela Zamudio y la poeta uruguaya y Directora de la Escuela de Aplicación en el Internado Nacional de Montevideo Adela Castell; las asistentes a las veladas limeñas como la chilena Amelia López de Soruco. Además quiero resaltar la participación de las mujeres peruanas con quienes se iniciara en su carrera literaria a través de su salón literario y el periodismo limeño. Entre ellas contribuyeron su gran amiga cusqueña, la escritora indigenista Clorinda Matto de Turner, la escritora arequipeña María Nieves y Bustamante y la educadora, también de Arequipa, Jesús Bustamante, las poetas Juana M. Lazo de Eléspuru y su hija Mercedes Eléspuru, las hermanas poetas Carolina García de Bambaren y Justa García Robledo, su querida amiga, la escritora beligerante y pianista Mercedes Cabello de Carbonera, la escritora y educadora Teresa González de Fanning, la ensayista Rosa M. Riglos de Orbegoso, la poeta y ensayista Juana Rosa de Amézaga, las asiduas concurrentes a las veladas Cristina Román de Palma, esposa de su gran amigo, el tradicionista Ricardo Palma; Eduvijes Sánchez de Corpancho, esposa del dramaturgo, poeta y ensayista Nicolás Corpancho; Mercedes O. de Sánchez Griñan, esposa del poeta Fernando Sánchez Griñan; y Josefina del Valle de Chacaltana, esposa del periodista y estadista Cesáreo Chacaltana.

El discurso que emana de las recetas revela la multiplicidad cultural latinoamericana y diferentes ideologías en su ostensible obra. Las recetas, en sí, ponen en relieve la diversidad cultural y lingüística, así como las distintas modalidades de expresiones regionales que circulaban en la segunda mitad del siglo XIX. Con gran orgullo patriótico algunas mujeres publican recetas indígenas con sus títulos respectivos en aymará o quechua: Edelmira Belzú (La Paz-Bolivia) ofrece la receta de «Humintas»; Margarita Córdova (La PazBolivia) "Conejo a la challa pampa»; Adela Zamudio (Cochabamba) «Conejo a la suma guarmi»; Cristina Román de Palma (Lima) «Pachamanca»; Clorinda Matto (Lima) «Chi- cha» $\mathrm{y}$ «Chicha de jora»; Hortensia Gutiérrez (La Paz) «Tecti». Otras recetas regionales que también definen la cocina nacional con gran patriotismo son la de, por ejemplo, Casiana Castro de Uriburo, que abre el recetario con estas palabras: «No habría de perdonarte, si no dieras el primer lugar en la sección -SOPAS- de este ecléctico libro, á la crema de las confecciones

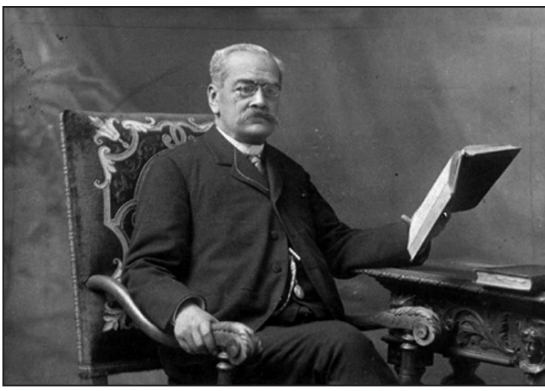

Ricardo Palma suculentas, á la nata de las cosas exquisitas, á la riquísima:- Sopa Salteña» (p. 155). Otros ejemplos de lo regional son los de Deidamia Sierra de Torrens (Metan) con su «Dorado a la San Martín»; Josefina del Valle de Chacaltana (Buenos Aires) con su «Tamal limeño»; Natalia R. de Dorado (Cochabamba) colabora con su «Pastel de Choclo a la Sucrense»; Rosa Hidalgo de Díaz (México) presenta «Cocido de gallina a la Mexicana»; Beatriz Lloza (Arequipa) «Estofado arequipeño»; Mercedes Cabello de Carbonera (Li$\mathrm{ma})$ presenta «Aceitunas [moqueguanas] rellenas»; Amelia López de Soruco (Santiago de Chile) «Cazuela»; Mercedes Torino de Pardo (Buenos Aires) «Churrascos»; Carmen Gazcón de Vela (Buenos Aires) «El mate»; Elisa Belmonte (Bogotá) presenta su «Piña a la bogotana». Otras colaboradoras contribuyen con recetas europeas «modernas» como Cármen Varas de Gras (Montevideo) con «Fritura a la diva»; Zoila T. de Vivero (Lima) «Pierna de carnero a la Napoleón»; Mercedes Cabello de Carbonera (Lima) «Estofado de Corbina». Además habría que agregar las recetas de la nueva ola de immigrantes como la de Eulalia Deheza de Carreño (Lima) «Sopa de té para desayuno", en la que le dice a su interlocutora: «Diz que no has vuelto á tomar té, desde haber gustado uno tan esquisito -regalo de un mandarin chino á un marino peruano, en cambio de una caja del sahumerio de Lima» (p. 167); Luisa Petit de Cavalier (Lima) «Tortilla a la bretona»; Catalina Pardini (Cocinera napolitana - Buenos Aires) «Macarrones a la calabresa»; o por último la «Ensalada polonesa» de María Waleiski subtitulada «(Recuerdos de la patria)».

\section{La escritura de la cocina o la cocina de la escritura $^{23}$}

En Cocina ecléctica una receta es también una estrategia discursiva que sirve para infun-
23

Aludo al título del ensayo de Rosario Ferré por lo que ella misma dice: «Lo que quiero decir con esto puede que huela a herejía, a cocimiento melítico, pero este ensayo se trata después de todo, de la cocina de la escritura. Pese a mi metamórfosis de ama de casa en escritora, escribir y cocinar a menudo se me confunden, y descubro una correspondencia sorprendente en ambos términos». Véase Rosario Ferré, «La cocina de la escritura», La sartén por el mango, Patricia Elena González y Eliana Ortega (eds.), Río Piedras, Ediciones Huracán, 1984 (pp. 137-54), p. 153.
Cartografías pan/americanas en Cocina ecléctica (1890) de Juana Manuela Gorriti

ROCÍO FERREIRA 


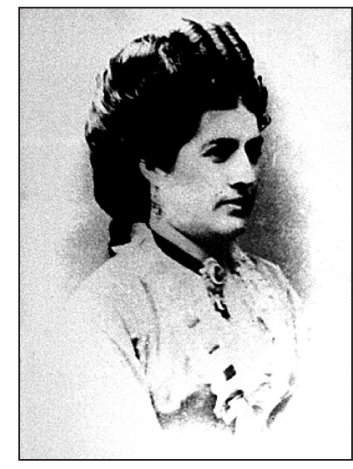

Mercedes Cabello de Carbonera.

24 Gorriti, Cocina ecléctica, op. cit. 25 Id. dir en los lectores contemporáneos una cierta ideología. Los temas que las escritoras peruanas Clorinda Matto de Turner, Mercedes Cabello de Carbonera y Teresa González de Fanning exponen en sus recetas se conectan intertextualmente con el resto de su obra. En ese sentido podemos apreciar el indigenismo y el anticlericalismo de Matto; el positivismo científico de Cabello y la preocupación por la educación femenina de González.

Cómo bien sabemos, en el proceso de la literatura peruana del siglo XIX, Clorinda Matto de Turner es una de las intelectuales y escritoras más importantes. Desde el comienzo hasta el final de su prolífica carrera escrituraria como poeta, ensayista, educadora, editora, traductora, organizadora de tertulias literarias, dramaturga y narradora, Matto luchó con tenacidad por preservar su postura ideológica frente a la población indígena, la cultura y lengua andina, el lugar de la mujer en las nuevas naciones, tanto como por autorizarse como intelectual, escritora y educadora en los proyectos modernizadores de posguerra de (re)construcción de la nación de una sociedad patriarcal conservadora -clasista, racista y sexista- que la relegaba por ser mujer, serrana y profesional. A lo largo de su trayectoria profesional, Matto siempre se mantuvo en el centro de la vida cultural y política republicana y nunca dejó de lado la misión que se propuso cumplir de «enseñar, predicar y conquistar el mundo de los ignorantes», como anunciara en su ensayo sobre la función del periodista en El Recreo del Cuzco en 1877. Con este lema, casi al final de su carrera escrituraria, tanto literaria como periodística, en el Perú, Clorinda Matto de Turner escogería cuatro de sus mejores recetas culinarias, «Sopa Teóloga», «Helado de Café», «Chicha», y "Chicha de Jora» como muestra simbólica de los temas de su interés para la compilación.

En su receta de la bebida andina más antigua y popular titulada «Chicha», al igual que en otros de sus textos como Tradiciones cuzqueñas, Hima-Sumac, Aves sin nido e Índole, Matto incluiría a la nación peruana, sobre todo, la cultura regional andina además de la limeña y la europea.

En «Chicha» Matto escribe:

Esta bebida hecha de maíz, el mas alimenticio de los granos, es el sosten de la vida y de la fuerza en el indio de las Sierras de Bolivia y del Perú. Con ella se alimenta; con ella se refresca, y con ella tambien se embriaga algunas veces, para olvidar sus miserias.

Se la confecciona de muchas maneras; pero las únicas usadas por aquellos pueblos serranos, son dos: la chicha primitiva o del Inca, hecha con el maíz fresco, y la chicha de Jora, que se hace con el maíz en germen ${ }^{24}$.

En esta receta la autora no sólo le da al lector una lección en nutrición, cultura y antropología andina sino que también le pide que comprenda el sufrimiento del indio y su situación, como también lo haría sobre la situación de la mujer en su obra. Además, en esta receta Matto relaciona el refresco del Inca significativamente con otros niveles de la sociedad y entreteje correspondencias estrechas con el resto de sus textos literarios. Matto decidiría dar a conocer al Perú y al resto de mundo la historia de la región sur andina -pero sobre todo de su querido Cusco-, poniendo especial atención en establecer la difícil situación de los indígenas y de la mujer, de denunciar todo tipo de corrupción, y de renovar la educación de la mujer en su vasta obra.

En su receta «Sopa Teóloga» Matto perfila ciertos rasgos de su tan discutido anticlericalismo, en el que criticara la ignorancia y la corrupción de los representantes de la iglesia católica. Vale la pena citar nuevamente a Matto:

Allá va, para figurar en la anunciada Cocina ecléctica, la más rica y sustanciosa confección que haya salido de manos de cocinero.

Parte integrante de las suntuosas comilonas con que los Padres Agustinos, de Lima, festejaban á los huéspedes invitados á sus conferencias teológicas, ha tomado el nombre de éstas [...]

Este nutritivo alimento, en el que la fracción líquida es tan fortificante, robustecería el cerebro de aquellos ínclitos varones, para investigar las nebulosas de esa ciencia -de nombre tan santo, y sin embargo tan vana- y revolotear, cual moscardones, sin comprenderla, en torno de la eterna luz: -Dios.-

Entre tanto, ruégote que hagas uso, tú de este poderoso agente de vida, para que pueda, conmigo, volver á verte esta Lima que te ama y te echa de menos ${ }^{25}$.

En este texto/receta/carta, haciéndonos recordar su postura crítica frente al obsceno comportamiento de los «malos sacerdotes» expuesta en sus novelas Aves sin nido (1889) e Índole (1981), la autora abiertamente estable- 
ce que, mientras es un desperdicio alimentar el cerebro de sacerdotes con una sopa tan nutritiva, sería más provechoso alimentar a mujeres lúcidas como a su querida amiga Juana Manuela Gorriti.

Por su parte, Mercedes Cabello de Carbonera publicaría cuatro recetas en el compendio culinario: «Estofado de corvina», «Aceitunas rellenas», «Ensalada de paltas» y «Helado de sangría» mostrando su diversidad creativa. Como bien sabemos Cabello fue una prolífica escritora de ensayos y de novelas, además de ser una gran pianista y cocinera. En la primera etapa de su carrera literaria, ya influenciada por el pensamiento positivista, publicaría un vasto número de artículos de carácter literario, pedagógico, filosófico y sociológico en los semanarios locales e internacionales. Ya desde este momento inicial de su producción filosófica, Cabello se ocuparía de evidenciar los males de su sociedad -el enriquecimiento ilícito, la obsesión de la nueva burguesía por el materialismo y las pasiones políticas-, y de defender los derechos de la mujer. En su segunda etapa literaria, dentro de las distintas corrientes filosóficas que circularan en la segunda mitad del siglo diecinueve, Cabello encontró en la ciencia del pensamiento positivista un arma para continuar analizando y combatiendo los defectos de la sociedad de su época abiertamente. Si al inicio de su carrera escrituraria como novelista, Cabello seguiría el consejo de Gorriti, su maestra y amiga, de escribir con «induljencia misericordiosa», con el paso de los años su escritura tomaría otro rumbo y con ella «haría temblar al mundo» "con esa picante sal epigramática» que su escritura novelística desplegara en múltiples direcciones y que sería precisamente la que la llevara al ostracismo en un medio intelectual represivo. No obstante, Cabello se volvería la novelista más prolífica del Perú decimonónico con la publicación de seis renombradas novelas. Fiel a su postura, Cabello continuó especulando sobre la ciencia y sobre la ineficiencia del discurso científico positivista que tendía a ver el cuerpo femenino como enfermo o inferior, y decidió presentar a las lectoras su receta «Helado de Sangría» para enseñarles a curar a un «marido de la embriaguez»:

Con el encanto misterioso que, segun antiguas crónicas, encierra esta sencilla confeccion, diz que madame Scarron, -después la célebre marquesa de Maintenon- curó á su marido de la embriaguez. El paralítico, para distraerse, en su inmovilidad, dió en beber, y diariamente se embriagaba. Maldita la gracia que hacía esto á una dama, desde ya, tan acicalada como madame Scarron. Pero que hacer. Necesario era contemporizar con aquella naturaleza humana en el pobre infirme que á ratos se aburría. Mas ¿para cuándo, la astucia diplomática de la mujer, sino para estos casos supremos?

$[\ldots]$

- ¡Ah! querido amigo, -dijo madame Scarron con voz temblorosa,- anoche en casa de Ninon be oido, en una disertacion cientifica entre dos célebres médicos, algo que ba sido para mi un aviso providencial. Dicen que la aproximacion de las sustancias que el vulgo humano llama vino, agua, hielo, azúcar, limon, canela y moscada, forma un todo extraño, que desde que es absorbido, se torna despótico, celoso de toda asimialcion (sic) de su género, si llega sin circunstancias atenuantes, y destruyendo al fin, no á su contendor, sino al recipiente que los recibe ${ }^{26}$.

En esta receta/relato como en otros ensayos que escribiera ${ }^{27}$, Cabello desafía el discurso de la ciencia al presentar a la mujer como la portadora de un efectivo conocimiento sanador del cuerpo y espíritu masculino enfermo. Además, apelando a la figura femenina capaz de combatir los males de la vida moderna, Cabello presenta una genealogía femenina que va desde Ninon de Lenclos, cortesana francesa-cuyo famoso salón fue frecuentado por librepensadores-, a Mme. Scarron, a la misma autora (Mercedes), a la compiladora (Juana Manuela), y finalmente va hasta las lectoras imaginarias con las que sostuviera un diálogo.

Por último, la educadora y escritora Teresa González de Fanning, quien dedicó su vida a la enseñanza de niñas y defendió el derecho de la mujer a educarse en sus numerosos ensayos y en sus tres manuales de educación, contribuyó con una receta sencilla peruana al compendio culinario de su amiga Gorriti. En su receta titulada «Migas», González de Fanning deja ver su vocación:

Sencillo y vulgar es, en su sentido radical, este plato de nuestra mesa peruana; su mérito está en la manera de confeccionarlo. Diferentes son; pero bé aqui una, deliciosa al gusto de mis pupilas; y que yo, fiando en la autoridad indiscutible del paladar infantil, ofrezco á las páginas de-COCINA ECLECTICA ${ }^{28}$.

En esta receta la educadora pone en primer plano el fallo de las estudiantes para autori-

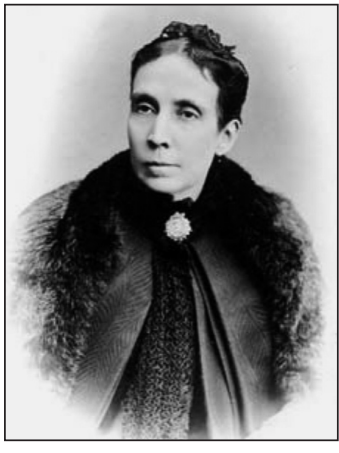

Teresa González de Fanning.

26

Gorriti, Cocina ecléctica, op. cit.

27

Me refiero específicamente $a$ «La mujer y la doctrina materialista», «Influencia de la mujer en la civilización» y «El positivismo moderno».

28

Gorriti, Cocina ecléctica, op. cit.

Cartografías pan/americanas en Cocina ecléctica (1890) de Juana Manuela Gorriti

ROCÍO FERREIRA 
zar la popularidad de su receta en el ámbito escolar.

Lo que hemos querido plantear en este trabajo es, que a través de las recetas culinarias, las mujeres no sólo entraron desde la casa al debate nacional sino que a su vez produjeron un lenguaje para comunicar sus perspectivas. En Cocina ecléctica, como en el resto de sus obras, las autoras del siglo XIX optarían por un pluralismo cultural al incluir diversas voces, regionalismos y variedad lingüística.

Con nuestro análisis del recetario culinario compilado por Juana Manuela Gorriti hemos mostrado la diversidad de discursos e ideologías que traen en sí las recetas de las autoras decimonónicas y cómo éstas, paralelamente, forman parte de un proyecto americanista. A través de ellas hemos recorrido la historia americana con el héroe de la emancipación humanizado; prácticas culturales que van desde el redescubrimiento del pasado andino, a lo que valoran de la religión, a la relación entre maestra y alumna, al gusto por la ópera y fascinación por sus «divas»; hasta lo más apreciado por las autoras: un fuerte, estrecho y duradero vínculo entre las mujeres. En este sentido, las recetas nos ayudan a entender con mayor profundidad la manera como estas mujeres imaginaron su época, su sociedad, su rol en ella y su ánimo por entregar una muestra heterogénea de nuestra América. 


\section{Apéndice: Selección de recetas}

«Dorado a la San Martin»

Diz que allá, cuando este héroe, en su gloriosa odisea, cabalgaba por los pagos vecinos al Pasage, un día, al salir de Metan, pronto á partir, y ya con el pié en el estribo, rehusaba el almuerzo que, servido, le presentaban llegó un pescador trayéndole el obsequio de un hermoso dorado; tan hermoso, que el adusto guerrero le dió una sonrisa.

Alentados con ella sus huéspedes:

- Ah! señor! -exclamaban, alternativamente.

- Siquiera estos huevos.

- Siquiera esta carne fria en picadillo!

- Siquiera estas aceitunas!

- Siquiera estas nueces!-

San Martin se volvio hacia sus dos asistentes:

- Al vientre del pescado - dijo- todas esas excelentes cosas, y en marcha!-

Dijo, y partió á galope [...] .

- Deidamia Sierra de Torrens (Metan)-

«Humintas»

De los cereales usados en la alimentacion humana, ninguno tiene tantas y tan excelentes aplicaciones, en todos los países de la America meridional, como el maiz. [...] La guatia es, en la huminta, como en todo asado, la mejor de las cocciones. Nuestro Chuquiapo arrastra en su corriente cantidad de piedrecitas rocallosas, que en su curso arranca á los peñascos.

Los indios hacen con ellas, colocándolas una sobre otra, un horno, en el suelo, que ahondan como diez centímetros de la superficie, y en cuyo centro encienden una fogata que atizan para dar intensidad al fuego, á fin de caldear las piedras.

- Edelmira Belzu de Córdoba (La PazBolivia)-

\section{«Pastelitos en Ayuno»}

Aunque la Santidad ilustradísima de Leon XIII ha levantado de nuestra conciencia un terrible peso al suprimir de los Mandamientos de la Iglesia, el más difícil de observar, tiene tal fuerza el poder de la costumbre, que siempre echaremos de menos el tiempo en que, atrevesando las penosas horas de la forma, aguardábamos el santo advenimiento de la colacion nocturna, que, á pesar del precepto, cuyo espíritu es: -mortificacion-, el buen gusto, sin quebrantarlo, sabia transformar en deliciosa cenita, compuesta de ensaladas y pastelillos delicadísimos, como el que contiene la siguiente receta:-[...]

-Águeda Álvarez. (Lima)-

\section{«Fritura a la Diva»}

No sé si los otros esperimentan lo que yo, á la aproximacion íntima de un ser superior.

Es algo, más que entusiasmo, más que admiracion. Es una mezcla de devoto fervor, de piadosa uncion, que torna adorable y sagrado cuánto han mirado sus ojos, cuánto han tocado sus manos, cuánto han hollado sus pasos.

Adelina Patti, ejerció en mí esa grata obsesion.

De Lisboa á Montevideo traíanos el mismo vapor; y en los dias de ese largo trayecto, era yo su sombra: la seguía por todas partes.

Habíala admirado en Covent Garden y la Grande Opera; y ora Julieta, ora Traviata, ora Semíramis, habíanme extasiado su voz y la sublime expansion de su genio, allá, en las elevadas regiones del arte.

Y ese ser divino estaba ahora, ahí, conmigo, en el reducido espacio de la cámara y el puente del vapor; platicando, riendo, fijando en mí, al paso, su mirada; alguna vez dirijiéndome la palabra, con esa voz que había electrizado al mundo.

Parecíame que una luz emanada de ella, lo embellecía todo en torno suyo. El agua que bebía era más clara, y el vaso que hubiesen tocado sus labios, más transparente. Los manjares de que ella gustaba, adaptábalos yo, y los saboreaba con delicia, á pesar de su sóbria confeccion.

Sin embargo, había uno que el cocinero llamaba: la «fritura de la diva» y que cada día lo servia, á ella sola, en la hora del lunch [...]

-Cármen Varas de Gras (Montevideo)-

«Salsa de Perejil»

[...] ¿Qué tal salsa, mi querida maestra? Esta confeccion, riquísima con el asado, la aprendí de una señora italiana, muy entendida en achaques de cocina.

-Lucila Cabello (Lima)-
Cartografías pan/americanas en Cocina ecléctica (1890) de Juana Manuela Gorriti 
«Seviche»

Recetaré un plato más, y me eclipso, dejando lugar á tantas confecciones deliciosas, que el sexo hermoso ha acumulado en este libro, y que -no fuera más que para saborearlas-dan ganas de vivir. ¡Benditas sean ellas, y las manos que saben hacerlas! [...].

-Urcina Ponce de Sandoval (Buenos Aires)-
«Estofado de Corbina»

Tengo este plato de un gastrónomo francés, compañero de Gambetta, aquel tribuno, diz que tan ducho en el arte de yantar, como en el de hablar.

Por supuesto, como de tan alto orígen, merece figurar en este libro de crema culinaria [...]

-Mercedes Cabello de Carbonera (Lima)- 